International Journal of Current Advanced Research

ISSN: O: 2319-6475, ISSN: P: 2319 - 6505, Impact Factor: SJIF: 5.995

Available Online at www.journalijcar.org

Volume 6; Issue 4; April 2017; Page No. 3515-3523

DOI: http://dx.doi.org/10.24327/ijcar.2017.3523.0306

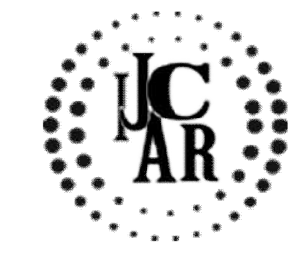

Research Article

\title{
GRADUATE STUDENTS' PERCEPTIONS OF SCIENTIFIC RESEARCH ETHICS IN UNIVERSITY OF NIZWA
}

\author{
${ }^{1}$ Hashemite University, Jordan \\ ${ }^{2}$ Kalema CBT Center, Jordan \\ ${ }^{3}$ Damascus University, Syria
}

Rana Al-Smadi ${ }^{*}$., Khawla Alsaida ${ }^{2}$ and Duha Aboud ${ }^{3}$

\section{A R T I C L E I N F O}

\section{Article History:}

Received $19^{\text {th }}$ January, 2017

Received in revised form $18^{\text {th }}$ February, 2017

Accepted 22 $2^{\text {nd }}$ March, 2017

Published online $28^{\text {th }}$ April, 2017

\section{Key words:}

Perception, Research Ethics, Omani Culture.

\begin{abstract}
A B S T R A C T
The purpose of this study is to investigate the perception of educational graduate students in the University of Nizwa towards scientific research ethics. A questionnaire was administered and distributed among educational graduate students at the University of Nizwa to measure their perception of research ethics. Numerical variables were reported as a mean \pm standard deviation, descriptive statisticT-test was also used for analyses of perceptionof graduate students' responses based on demographic variables of gender, age, and the educational master program. The results of the study revealed that graduate students' perception of research ethicsis moderate in most of the dimensions of the questionnaire, and there were significant differences among graduate students' perception for the favor of male students in the first three dimensions, and there were no significant differences among graduate students' perception in age and educational master program. This study presents information to the university administrators to determine how graduate students should be have towards research ethicsand to reinforce the importance of research ethics, the study also contributes to the body of research on research ethics from the Omani cultural context.
\end{abstract}

Copyright $@ 2017$ Rana Al-Smadi et al. This is an open access article distributed under the Creative Commons Attribution License, which permits unrestricted use, distribution, and reproduction in any medium, provided the original work is properly cited.

\section{INTRODUCTION}

The term "research" could simply be defined as the scientific analytical thinking, which follows a systematic methodology in various stages, that characterized by objectivity and accuracy to generate new knowledge/facts or new explanation of relationships, that help in developing humans' understanding of the world and the quality of their living (Albaroudi, 2013; Alebaikan \& Alsemiri, 2016; Boehm, Justice \& Weeks, 2009; Elsayed \& Kass, 2007; Hastings, Stockley, Kinderman \& Egan, 2017;Research \& Enterprise Development Centre, 2014 ). Reasoning scientific thinking can be achieved eitherby inductive or deductive approaches (Couvalis, 2004; Henrik \& Klauer, 2011), that differby the way of studying the phenomena by descriptive or exploratory methods, in quantitative or qualitative data during research conduction. Scientific research is structured as a process of comprehensive outlinesto achieve certainultimatescience objectives such as: explanation of why certain things are happening and try to understand and evaluate causes by observation and description (Burns, 1994; Kandeel, 2014); prediction of the causes/relationships that could attribute of

*Corresponding author: Rana Al-Smadi

Hashemite University, Jordan things to be happened (Kerlinger, 1986) and controlling by embracing reason and logical validity and experimental verification (Al-Baroudi, 2013; Skaik, 2014) to effort new knowledge. Hence, nations have assigned huge budgets on establishing "community of inquiry" (Anfara \& Mertz, 2006) as they realized the greatness of its benefits in the local and international level and its contributions in progress.

It is very important that research involving human \animal participants should be carried out by individuals who should possess:(1) scientific competence which is referred to selfidentification and realization as a researcher that formed and frame worked researcher' specialized vision and behavior toward research nature, responsibility and process (Couch \& Dodd, 2005; Kruck, 2013) to pose the right research questions. (2) Logical competence refers to researcher rational thinking of research problem and the determination of the need to study it by analyzing its different factors and circumstances (Albaroudi, 2013, Elsayed \& Kass, 2007) with an intellectual curiosity. (3) Operational competence embeds researcher's capabilities to develop plan of the appropriate methodology and method(s) (Kandeel, 2014) to address research problem. (4) Action competence contains the ability to implement the efficient procedures including data collection and analysis and interpretation of the results (Alqarni, 1418H), (5) the Evaluation and Professional 
competence (Johnson, 2014) that embeds researcher ethics to review the whole process and results for generalization and publication of the research.

Scientific research is mainly based on investigating and exploring knowledge and facts that aim solving problems, making changes and developing societies, therefore, studying research ethics (Cohen, Manion, \& Morison, 2007; Couch \& Dodd, 2005) and addressing ethical principles and responsibilities have become more important than ever in maintaining the insight track of research methodology and methods that controls the vital research activities. The term "Ethics" refers in general tothe values that guide people's actions which help them to be able to distinguish between right and wrong which in turn help them to act in acceptable behaviors or unacceptable behaviors, that for the most part, ethics establish standards of conduct in all life aspects (David \& Resnik, 2015). Hence, many organizations establish ethics code for that governs their activities and members, for instance, there are ethical code governs conduct in medicine, law, engineering and business (Albaroudi (2013; David \& Resnik, 2015); people who conduct scientific research have alsoresearch ethics code govern their activities.

Giving the fact of the importance of scientific research, universities are making great efforts to enrich students' inquiry capabilities by educate and train them to master scientific research skills (Couch \& Dodd, 2005; Davis, 2003; De Russy, 2003) which enable them to investigate by stimulating their intellectual, critical and scientific thinking to discover new facts and knowledge. As a result, students could evaluate and define the methodology and methods used in their research to achieve its aims. Unfortunately, (Alhabeeb \& Alshumari, 2014; Miller,1983) mentioned that students in the educational science faculty still suffer weak in choosing the suitable methodology, moreover, "conflict of interest or misconduct behaviors such as plagiarism, fabrication, and falsification of data, became part of the scientific research" (Kruk, 2013, p. 27), unethical behaviors occurs at many universities where dishonest-students and their actions successfully disrupt the learning process (Boehm, Justice \& Weeks, 2009; Yusof, 2009) and cause violation in the relevant scientific conventions.

University of Nizwa, as other universities and colleges, has providedan ethical code manifesting the values and principles that govern conducts of all university members to establish a learning environment. This ethical code contains some regulations related to guiding ethics and intellectual property and copyright policy (University of Nizwa, 2013; 2015), and is responsible for implementing, monitoring and assessing all research issues. The purpose of the guidingethics codeis to identify the various categories of academic misconduct which present "as any behavior whatsoever perpetrated by any member of an academic institution in relation to any item of assessment which may compromise the purposes of the assessment" (UoN- R \& R-AMP, 2010, p. 58-59).

All the academic misconducts mentioned in the guiding ethics of university of Nizwa are following the standard categories academic misconduct for institutions in Omani higher educations, (a) plagiarism which may occur by quoting from someone else's work without acknowledging and referencing the name of the original author or source, (b) copying any material attributable to another author or source as self-own, or making small modifications on the original material then submit it as self-own, (c) collusion with others to present student's research as one's own, (d) replication by submitting a work done in a previous course as if it is a new work without the prior consent of the course tutor, (e) forgery means fabrication of data whether originating from lawful or unlawful source, and (f) counter feiting refers to using of counterfeited academic documents for the purposes of fraud, deceit, deception and gaining unfair personal advantages.

Although it was clearly mentioned and documented the academic misconducts and the procedures and penalties that are proportionate to such behaviors, university of Nizwa is still responsible for informing students to avoid and not be engaged in those misconducts and is obligated to encourage students to be involved in presenting original and beneficial papers to develop society. University of Nizwa's guiding ethics didn't address the responsibilities and behaviors that researcher should follow during research process and different stages, moreover, the guiding ethics didn't mention anything related to humanlanimal participation in research, thus, this could make graduate students not be fully aware of the importance of such responsibilities and behaviors, in addition, this may make students interpret ethics according to each understanding and experience and how they perceive research ethics as a concept.

Thus, identifying students' perception of scientific research ethics will present specific information to the deanship of graduate studies at university of Nizwa to pay more attention to the ethical issues that students may grapple with, and to develop effective strategies for ensuring scientific research ethical responsibilities to avoid misconduct activities and to establish a manual describing the ethical principles for scientific research involving human participants.

\section{What is ethics in scientific research? And why it is important for graduate students?}

Dictionary of Sociology (1998) defines research ethics as "the application of moral rules and professional codes of conduct to the collection, analysis, reporting, and publication of information about research subjects, in particular active acceptance of subjects' right to privacy, confidentiality, and informed consent". Thus, research ethics refer to the commitment of researcher during conducting his her research towards specific responsibilities and behaviors (Elsayed \& Kass, 2007) that are stressed by norms and values while seeking to accomplish work, Tangen (2013) cited that " research ethics refers to a complex set of values, standards, and institutional schemes that regulate scientific activity" (p. 678).

Reviewing scientific research ethics literature concerning humans lanimals participation (Couch \& Dodd, 2005; Marshall \& Garry, 2005; Pring, 2000; Spaulding, 2009; Stutchbury \& Fox, 2009; WCRI2013, 2013; Yusof, 2009) could challenge researchers by two main categories of principles and responsibilities which take place at variety of levels:research ethics principles concerning researcher's personal norms and values (micro level) and research ethics principles concerning research framework (macro level). While Alebaikan \& Alsemiri (2016) labeled the research ethics principles by the term (integrity) which has twofold domains, first which concerns researcher's personal ethics that are guided by 5 principles; honesty, confidentiality, fairness, 
respect and responsibility during conducting a research involving human participants, and second integrity in scientific principles which carried out by an aim to develop or contribute to knowledge and not related to any academic misconducts such as (plagiarism, fraud and fabrication of data).

Likewise, Albaroudi (2013) revealed that there are certain main ethical principles that should carried out by researchers; well-prepared and trained and having competences of conducting research; honesty, objectivity; responsibility, respect of human rights. Kruk (2013) mentioned that "research ethics involves the application of fundamental ethical principles to a variety of topic involving scientific research. These include the design and implementation of research involving human experimentation" (p. 26). Kruk cited that research ethics principles such as honesty, objectivity, integrity carefulness, openness, responsibility should be considered in all the stages of research while dealing with human $\backslash$ animal participation, which "allows them to make ethical decision, linked to responsibility, honesty, and fairness. It is also very important "for students to learn competence in using the research results of other person in accordance with national, international law" (p.27).

Reviewing the previous literature concerning research ethics especially in the Arab World, we can noticed that the stress was on the "micro level" which concerning the personal norms of researcher and a little of how helshe should deal with humans as participants, and it was rarely mentioned about the "macro level" which concerning the academic responsibilities. Therefore, the following is a rough and general ethical principles and responsibilities that educational researcher should be aware to in each stage while conducting a research:

Research ethics responsibilities that formulating and clarifying research problem, which starts from the personal feeling of the existence of research problem which is defined as the "knowledge gap" and the need to address it, which makes the researcher going beyond just accomplishing his/her work and just for the purpose of research to become for the benefit of humanity and society. This stage contains certain steps of identifying the attributes of a good research topic; generating ideas that help researcher to select a beneficial topic (Kruck, 2013), and turning ideas into clear research questions and objectives.

It is essential in this stage to submit something new in the research, new idea, new knowledge and new fact that highlight the importance of addressing such research problem. Something new doesn't always mean that there is no one studied it before (Alshayeb, 2005), but it means that the aspect from which the problem is willing to be studied is new. It is very beneficial to continue the work of other researchers and review literature to understand how others have approached or dealt with the problem; since science is accumulated and changeable and seeks to develop communities (American psychological association, 2010). Therefore, research problem should be realistic and vital, and this requires that researcher should be involved in the aspects of his/her organization and society to acknowledge the real needs and demands that reach to its welfare and comfort, and also to increase resources for ensuring and writing the research.
Research ethics responsibilities during literature review. Conducting a research is guided from general idea of the problem to specific area, there should be enough review of the priorresearchers' efforts. In this stage, researcher should acquire critical, intellectual and analytical thinking skills. Research problem "knowledge gap" does not only depend on personal experience; it should also emerge from the previous findings of studies that concluded and recommended searching in such area, therefore, reviewing previous studies should be according to scientific professional reading (Ala'wad, 2013; Obaidat et al., 1992) that starred with critical and analytical thinking to clarify of what is read and to highlight the main thoughts.

In this stage in reviewing the related literature of specific issue, researcher should reorganize, reinterpret and reevaluate the previous literature for many rational reasons; for the purpose of making sense that the topic is related and consisted with the prior studies, for the purpose of tracing the descriptive patterns in other work to identify the knowledge gap and the argument that has not been explored (Almakbeel, 2011) for the purpose of defining the terminology and for the purpose of providing an analytical review of findings and recommendations to fulfill a rational need for additional research.

Research ethics responsibilities that describing methodology of the research. Research methodology is referred to a set of scientific approaches which imply theoretical analysis to underline the ontology and epistemology that researchers used to seek the reality and organize efforts to explain how research questions and hypotheses will be answered and accurately predict of the results (Anfara \& Mertz, 2006; Lavallee \& Lesilie, 2017). Research methodology is based on the nature of a field of the study; more than self-preferences or abilities which could lead to a bias of selecting inefficient and inappropriate research' tools and methods for collecting data which in turn may lead to incorrect results because it doesn't assess what is supposed to be measured (Miller, 1983) Therefore, citing appropriate literature could help in determining and justifying the suitability of choosing particular methodology.

Moreover, in this stage there are some considerations for ethical responsibilities including the following: researcher should have enough knowledge and information of research various methodologies and when to use each; researcher choice should depend on ethical action. It is essential that in this stage that research questions $\backslash$ hypotheses should clearly identify the purpose of the study (Stutchbury \& Fox, 2009). Research question(s) is the thing that the research set out to answer, whereas, research hypothesis(s) is a clear statement to identify the relationship between two or more variables. The methodology and the methods used to conduct a research depend upon the research questions lhypotheses being asked and underpinned. Also, researcher should know the differences between qualitative and quantitative study design and the applications of each one and be able to justify why choosing particular approach.

Research ethics responsibilities in collecting data in an organized and controlled manner. Collecting data in scientific research depends on the methodology that researcher uses to answer research questions and test the hypotheses, therefore, it is important to assess the degree of researcher's 
commitment in the required ethical responsibilities in collecting data stage. The ethical responsibilities could be limited into two main aspects; (1) knowledge of collecting data methods, (2) values and behaviors during collecting data (Pupovac et al,. 2008; Smith, 2003; Stern \& Elliott, 1997). Having knowledge about the various methods according to research methodology and recognize the use of each is essential, the choice of the appropriate method vary according to the methodology and questions of the research. Moreover, having less knowledge of collecting data methods could lead to choose sample may not fully represent the problem that have to be solved, which in turn use fewer search sample which gives non-scientific value data or general application (Ekahitanond, 2014; Smith, 2003; Stern \& Elliott, 1997) and which may lead to inaccurate results.

Research ethics responsibilities in analyzing and interpreting results Data analysis is "the process of bringing order, structure and meaning to the mass of collected data...., data analysis is a search for answers about relationships among categories of data " (Marshall \& Rossman, 1990, p 111), while data interpretation refers to " the process of attaching meaning to the data" (Marshall \& Rossman, 1990,p 111). Moral researcher must analyze and interpret his her results which are scientifically ethical (McNamara, 2017) by reviewing research objectives. In this stage, researcher should tie discussion to the literature, determining the conclusions, significance, and implications of the findings (Stutchury \& Fox, 2009).

Thus, colleges and universities "are being called to educate and influence the ethics of future leaders" (Boehm, Justice \& Weeks, 2009, p. 47), Couch \& Dodd (2005) challenged that colleges and universities have the responsibility for culturing professional ethics among future employees as students " receive in their colleges and universities\} their first exposure to ethical standards and traditions" (p. 20). Undeniable, graduate students should be more aware of research ethics during research various stages as they are considered as "researchers-in-training" (Hastings, Stockley., Kinderman., \& Egan, 2017; Villatoro, Chang, \& Lane, 2014; Pupovac et al., 2008), and who participate in the sustainable development of the society.

Unfortunately, (Couch 7 Dodd, 2005; Ismael, 2010; Alebaikan \& Alsemiri, 2016) asserted that it becomes common among graduate students in the universities to conduct unethical activities especially plagiarism, which refers to the appropriation and the use of another person's work by ideas, processes, results, or words without giving appropriate credit. Boehm, Justice \& Weeks (2009) mentioned that unethical behavior occurs at many colleges and universities "where dishonest students and their actions successfully disrupt the learning environment" (p. 46)."Some administrators emphatically point to the internet as a major culprit for increased academic dishonesty" (p. 46), the abundance of the electronic resources in the internet is the main cause for such behavior, Yusof (2009) cited that there is significant difference in the definition of plagiarism according to the cultures of graduate students, whereas students from China and Spain mentioned that they don't consider it as unethical activity in their home culture.

Likewise, Almakbeel (2011) stressed also that the academic climate and culture influence students' concept of plagiarism, whereas supervisors play a crucial role in this toward guiding their students, and the lack of essential skills such as critical thinking, faculty members agree that lack of training and communication, have played a role in dishonest conduct within academia.Owing to the fact that students and young scientific participating in research have not passed through formal special training in ethics education, it is important to discuss ethical standards during the presentation of students' projects or during preparing of dissertation. Kruk (2013) mentioned that "unfortunately, dishonesty and integrity of data, conflict of interest or misconduct behaviors, such as plagiarism, fabrication, and falsification of data, became part of the scientific research" (p. 27).

Elsayed \& Kass (2007) conducted a study which aimed to explore the knowledge of researchers concerning ethical issues. The study used a descriptive cross-sectional design and data was collected through in -depth interviews with more than 200 master students. They concluded that ethics in research systems in Sudan has never been evaluated, and 87\% of respondents claimed that they heard of ethics; $38 \%$ of them heard of ethics from their basic education; $15 \%$ of them heard of ethics as they attended courses in the university, and the average duration of these courses is 2 weeks. Participants showed deficient knowledge about research ethics and ethical principles. Most of the previous findings of (Elsayed \& Kass, 2007) could be generalized on many other students in the Arab universities which stillhave been criticized on the way of recognition of the importance of research (Ala'wad, 2013; Albaroudi, 2013; Alebaikan \& Alsemiri, 2016; AAlhabeeb \& Alshumari, 2014; AAlmakbeel, 2011; Alqarni, 1418H, Alshayeb, 2005) and on not meeting the international research ethics guidelines.

\section{Significance of the study}

Even though there is a general code of ethics at the University of Nizwa, regulations that related to scientific research ethics focuson citing resources and avoiding plagiarism in a brief way.Moreover, ethics in university of Nizwa has never been evaluated and therehas never been any feedback reportingwhether graduate students' perceptions are meeting the international scientific research ethics principles and responsibilities, especially that a lot of scientific misconduct behaviors such as plagiarism, fabrication and falsification of data (Kruk, 2013) occur at many colleges and universities around the world which disrupt the learning environment (Boehm, Justice \& Weeks, 2009). Therefore, there is a need to explore graduate students'perceptions of such ethical behaviors to report a revisit to the code of ethics of the university. Therefore, it is expected that by identifying the degree of students' awareness of research ethics that they themselves could highly be committedin their research process to develop fruitful experience and professional growth.

Also, this study is expected to contribute to the current international and regional literature (Aaron, 1992; Ala'wad, 2013; Albaroudi, 2013; Almakbeel, 2011; Hastinngs et al., 2017; Lavallee \& Lesilie, 2017; Macfarlane \& Saitoh, 2008; Miller, 1983; Obaidat et al., 1992) on research ethicstowards increasing awareness and improving the effectiveness of research, especially it is way difficult to find any reference to research ethics in Oman. Therefore, it is expected that this study will support more of the institutional involvement for 
formal instruction in research ethics. Moreover, this study contributes by empirical data on exploring the perception of research ethics in non-Western country, which highlights the potential of exploring the role of scientific research ethics in society development.

\section{The research objectives and questions}

This study aims at investigating educational graduate students' perceptions in university of Nizwa towards scientific research ethics principles. The principles havebeen determined according to the following five domains: research ethics during formulating and clarifying research problem, research ethics during reviewing theoretical literature, research ethics during describing methodology of the research, research ethics during collecting data in an organized and controlled manner and research ethics during analyzing data and interpreting results. Focusing more narrowly, this study addresses the following questions:

1. Whatis the degree of perception for graduate students at the education and cultural studies department of scientific research ethics principles?

2. Are there significant differences among graduate students' perception of scientific research ethics and their following individual demographics: (gender), (master program) and (age)?

\section{Methodology of the study}

This study is quantitative in nature and was conducted using descriptive methodology and survey as a tool, means, standard deviations, t-test were utilized in this study.

\section{Participants}

The population of this study includes all master graduate students in the education and cultural studies department (education administration program, education in psychological guidance \& counseling program, education in curriculum and teaching methods program and education for teaching Arabic to speakers of other languages program) in the college of Arts \& Science at University of Nizwa in Oman. The three researchers decided to exclude first semester enrolled students because they were not yet exposed to research experiences and to issues related to scientific research ethics. Therefore, a few of students in curriculum and teaching methods program participated in this study, whereas, students in education for teaching Arabic to speakers of other languages program were completely excluded because all of them were in the first semester, and students whoare enrolled in the first semester from educational administration and Education in Psychological Guidance \& Counseling programs have also been excluded.

Table 1 Enrolled \& Registered Master in Education and Cultural Studies Department in fall 2016

\begin{tabular}{cccc}
\hline Count of Student & \multicolumn{3}{c}{ Gender } \\
\hline College/ Major & Female & Male & Total \\
Arts and Sciences & 238 & 308 & 546 \\
Education in Psychological Guidance \& & 162 & 154 & 316 \\
$\quad$ Counseling & 10 & 34 & 44 \\
M.ED In curriculum and Teaching Methods & 10 & 29 & 38 \\
MA in Education for Teaching Arabic to & 9 & 91 & 148 \\
$\quad \begin{array}{c}\text { Speakers of other Languages } \\
\text { Master in Education Administration }\end{array}$ & 57 & 308 & 546 \\
\hline Total & 238 & &
\end{tabular}

As mentioned in table (1) the target population of the research consists of all master graduate students in the education and cultural studies department in the college of Arts \& Science at University of Nizwa in Oman,a total of 546 students most of them from education in psychological guidance \& counseling program and most of them are males.

Table 2 Demographics of the Sample

\begin{tabular}{ccccc}
\hline Variables & & No. & Percentage & Total \\
\hline \multirow{2}{*}{ Gender } & Female & 68 & $46 \%$ & \multirow{2}{*}{148} \\
& Male & 80 & $54 \%$ & \\
Age & Less than35 & 79 & $53 \%$ & \multirow{2}{*}{148} \\
& more than 35 & 69 & $47 \%$ & \\
\multirow{3}{*}{ Master Program } & administration & 92 & $62 \%$ & \multirow{2}{*}{ counseling } \\
& curriculum and & 51 & $35 \%$ & \\
& teaching methods & 5 & $3 \%$ & \\
\hline
\end{tabular}

Questionnaires were distributed to a convenient sample of 148 graduate students during fall semester 2015-2016, most of them were males and less than 35 years old. The majority of the respondents $(62 \%)$ were from the education administration, 38\% were from counseling and $3 \%$ from curriculum and teaching methods.

\section{Instrumentation}

For the purpose of the study which is to investigate the degree of graduate students' perceptionof scientific research ethics principles; therefore, a quantitative approach is implemented using survey methodology. The researchers employed Graduate Research Quality questionnaire which was developed by (Alhabeeb \& Alshumari, 2014), and was consisted of 60 items distributed in 5 dimensions (1)research ethics during formulating and clarifying research problem,(2) research ethics during reviewing theoretical literature, (3)research ethics during describing methodology of the research, (4)research ethics during collecting data in an organized and (5)controlled manner and research ethics during analyzing data and interpreting results. The questionnaire utilized a three-point Likert- scale ranging from 1 to 3 " disagree" to "strongly agree".

Alhabeeb \& Alshumari (2014) applied statistical testing to determine the underlying dimensions of the awareness of research ethics and to assess the instrument's validity and reliability. According to (Alhabeeb \& Alshumari, 2014) reliability for the 60 items is high with a coefficient alpha of (0.97). Further, computed coefficient alphas for each subscale was: (1) research ethics during formulating and clarifying research problem $0.88,(2)$ research ethics during preparing theoretical literature 0.94 , (3) research ethics during describing methodology of the research 0.96 , (4) research ethics during collecting data in an organized and controlled manner 0.95 and (5) research ethics during analyzing data and interpreting results 0.98 .

In order to assure the psychometric properties of the questionnaire in the Omani culture, internal consistency measures of reliability were computed for the instrument by calculating Cronbach's alpha coefficient. As a result, the internal consistency rating for each subscale dimensions (1) research ethics during formulating and clarifying research problem $0.88,(2)$ research ethics during reviewing theoretical literature 0.94, (3) research ethics during describing methodology of the research 0.96 , (4) research ethics during collecting data in an organized 0.95 and (5)controlled manner 
and research ethics during analyzing data and interpreting results 0.98 , and the internal consistency for the 60 items scale was 0.97 .

\section{Findings of the study}

The purpose of this study was to investigate the graduate students' perceptionof scientific research ethics principles and responsibilities, and the impact of demographic differences on their perceptions. This was a quantitative study using descriptive statistical analysis to address two research questions:

Q. 1. Whatis the degree of perception ofgraduate students at the education and cultural studies department of the scientific research ethics? To address this question, table (3) displays the descriptive statistics for all responses of (148) graduate students on the five dimensions of the questionnaire. Participants responded to 60 items on based on three levels of agreement $(1=$ low (1.00-1.66), 2 = moderate $(1.67-2.33), 3=$ high (2.34-3.00). Mean scores were calculated for the overall response and for each dimension of the questionnaire.

Table 3 Questionnaire Overall and Dimensions Mean Scores.

\begin{tabular}{ccccc}
\hline & $\mathbf{N}$ & $\begin{array}{c}\text { Std. } \\
\text { Deviation }\end{array}$ & Mean & \\
\hline $\begin{array}{c}\text { formulating and clarifying } \\
\text { research problem } \\
\text { preparing theoretical }\end{array}$ & 148 & 0.61465 & 2.2179 & Mid \\
$\begin{array}{c}\text { literature } \\
\text { describing methodology } \\
\text { collecting data }\end{array}$ & 148 & 0.51813 & 2.2117 & Mid \\
$\begin{array}{c}\text { analyzing data and } \\
\text { interpreting results } \\
\text { total }\end{array}$ & 148 & 0.46555 & 2.2 & Mid \\
\hline
\end{tabular}

Table (3) showed the means and standard deviations of the five dimensions of the Questionnaire and the mean of the Questionnaire in general were all moderate with SD .423. The lowest mean was 2.059 for the dimension analyzing data and interpreting results with SD .418 , and the highest mean was 2.217 for formulating and clarifying research problem with SD .614, this indicates that the commitment of students toward research ethics is moderate.

In the first dimension (formulating and clarifying research problem) the item which addresses (student isliterally committed to proposal plan unless it is changed by the supervisory committee) got the only high level with 2.378 and SD 0928, whereas the item (student prepares the proposal plan by him ไherself without referring to previous proposals) got the lowest level with 1.675 and SD .949. In the second dimension (preparing theoretical literature) the item (student don't comment by any ironic words toward other researchers' work) got the highest level with 2.53 and SD2.27, whereas the item (student mentions the opinions that differ of his her opinion) got the lowest mean 1.797 with SD .982 .

More likely, in the third dimension (describing methodology) the item which addresses (student gets formal letters to and from the organization that will be studied) got the highest mean 2.486 with SD .876, and the item (student obtains written permission to use a research tool) got the lowest mean 1.783 with SD .979. In the fourth dimension (collecting data) the item (student choose the statistics according the objectives of the study) got highest mean 2.324 and SD .949, whereas the item (student avoids hiding weak data in order to manipulate the result of the study) got the lowest mean 1.770 and SD .976.Finally, in the fifth dimension (analyzing data and interpreting results) the item (student writes study recommendation according to the results of the study) got the highest mean 2.459 with SD .891, whereas the item (student mentions the error in his $\backslash$ her research and how it impacts his $\backslash$ her research credibility) got the lowest mean 1.973 with SD 1.00.

Q.2. Are there significant differences among graduate students' perception of scientific research ethics and their following individual demographics: (gender), (type of master) and (age)?T-testswere used to investigate the difference in means between males and females, between students in counseling master and administration master and between age less than 35 and more than 35 , it should be aware that the $3 \%$ of students in curriculum and teaching methods program have been excluded from the analysis because it will not be statistically significant of comparison.

Table 4 differences between students' perception males and females in each dimension

\begin{tabular}{ccccccc}
\hline & gender & $\mathbf{N}$ & Mean & Std. Deviation & Sig. & $\mathbf{T}$ \\
\hline \multirow{2}{*}{ Dimension 1 } & female & 68 & 2.1941 & 0.45751 & $.004^{*}$ & 0.38 \\
& male & 80 & 2.2267 & 0.56704 & & \\
Dimension 2 & female & 68 & 2.0147 & 0.37427 & $.014^{*}$ & 1.202 \\
& male & 80 & 2.0975 & 0.45115 & & \\
Dimension 3 & female & 68 & 2.2022 & 0.5669 & 0.325 & 0.286 \\
& male & 80 & 2.2312 & 0.65576 & & \\
Dimension 4 & female & 68 & 2.1647 & 0.4178 & $.021^{*}$ & 0.85 \\
& male & 80 & 2.23 & 0.50326 & & \\
Dimension 5 & female & 68 & 2.1303 & 0.56377 & 962 & 0.02 \\
& male & 80 & 2.1321 & 0.5935 &. & \\
total & female & 68 & 2.1412 & 0.37846 & 0.054 & 0.604 \\
& male & 80 & 2.1835 & 0.4604 & & \\
\hline
\end{tabular}

However, table (4) illustrated that there were significant differences at the 0.05 level between males and females in the dimensions formulating and clarifying research problem, preparing theoretical literature, and collecting data for the favor of males.

Table 5 differences between students' perception in master program

\begin{tabular}{ccccccc}
\hline & ma & N & Mean & $\begin{array}{c}\text { Std. } \\
\text { Deviation }\end{array}$ & T & Sig. \\
\hline Dimension 1 & Counseling & 92 & 2.2072 & 0.49391 & 0.036 & 0.363 \\
& Administration & 51 & 2.2105 & 0.55799 & & \\
Dimension 2 & Counseling & 92 & 2.0543 & 0.39569 & 0.034 & 0.157 \\
& Administration & 51 & 2.0902 & 0.45486 & & \\
Dimension 3 & Counseling & 92 & 2.2174 & 0.56478 & 0.472 & 0.091 \\
& Administration & 51 & 2.2353 & 0.69536 & & \\
Dimension 4 & Counseling & 92 & 2.1859 & 0.44711 & 0.157 & 0.501 \\
Administration & 51 & 2.2314 & 0.48764 & & \\
Dimension 5 & Counseling & 92 & 2.1677 & 0.5402 & 0.55 & \\
Administration & 51 & 2.0532 & 0.62725 & & 0.198 \\
total & Counseling & 92 & 2.17 & 0.38075 & 1.097 & \\
& Administration & 51 & 2.16 & 0.4837 & & $.043 *$ \\
\hline
\end{tabular}

Table (5) revealed that there were no significant differences at the 0.05 level between counseling master students and administration master students' perception of research ethics on each dimension of the questionnaire, unlikely, results reported that there were significant differences in the total of students' awareness according to their master specialization for the favor of counseling students program.

Table (6) revealed that there were no significant differences at the 0.05 level between students who are less than 35 years old and students who are more than 35 years old' awareness towards research ethics on each dimension of the 
questionnaire, unlikely, results reported that there were only significant differences in the total of students' awareness according to their age for the favor of less than 35 years old.

Table 6 differences between students 'perception according to their age

\begin{tabular}{ccccccc}
\hline \multicolumn{1}{c}{ Age } & N & Mean & $\begin{array}{c}\text { Std. } \\
\text { Deviation }\end{array}$ & t & Sig. \\
\hline \multirow{2}{*}{ Dimension } & 1 More than35 & 79 & 2.2 & 0.49889 & 0.293 & 0.368 \\
& Less than 35 & 69 & 2.2251 & 0.5427 & & \\
Dimension & 2More than35 & 79 & 2.0962 & 0.40365 & 1.145 & 0.446 \\
& Less than 35 & 69 & 2.0174 & 0.43351 & & \\
Dimension & 3More than35 & 79 & 2.1646 & 0.60432 & 1.131 & 0.916 \\
& Less than 35 & 69 & 2.279 & 0.62505 & & \\
Dimension & 4More than35 & 79 & 2.1873 & 0.44989 & 0.353 & 0.316 \\
Dimension & Less than 35 & 69 & 2.2145 & 0.48576 & & \\
& 5More than35 & 79 & 2.0922 & 0.55613 & 0.879 & 0.958 \\
Total & Less than 35 & 69 & 2.176 & 0.60319 & & \\
& More than35 & 79 & 2.15 & 0.37234 & 0.49 & $.046 *$ \\
& Less than 35 & 69 & 2.18 & 0.47821 & & \\
\hline
\end{tabular}

\section{DISCUSSION}

Educational research involving human subjects should be carried out by qualified researchers and in accordance to the appropriate methodology with sample size sufficient to give accurate results and processed statistically, precision tools and devices used in writing scientific references that have been used by all credibility. "Researchers need to be mindful of rules, laws and codes of conduct which determine how to behave whilst they are conducting their research. At another level, it can be argued that maintaining the integrity of the research is itself an ethical issue" (Stutchury \& Fox, 2009, p. 489).

The results of this study revealed that the perception of graduate students in university of Nizwa exists but it is not high level which indicts moderate level to affect students' awareness and commitment during conducting research stages seriously, which may involve them in misconduct activities, "academic misconduct happened because student has no idea what they doing" (Ekahitanond, 2014, p. 151). This result could be supported by what Almakbeel (2011) mentioned that the academic climate and culture influence students' concept of misconduct activities, and supervisors play a crucial role toward guiding their students of research ethics. Although the five dimensions of the perception were moderate, the dimension- formulating and clarifying research problem- got the highest mean, whichcould indict that graduate students in this stage of the research could reflect on the research problem or knowledge gap and couldspecify the main variables of the research problem, especially that there is a seminar for approving the title of the research proposal by all faculty members.

However, collecting data and analyzing and interpreting results were the dimensions of lowest means, it should be noted that graduate students depend in general on the descriptive approach and the survey tooland theyare weak in statistics analysis which leads to weak in analyzing and interpreting results. Moreover, graduate students don't critically reflect on the literature review in their analysis and interpretation of the results, hence, they depend on their personal justification and experience.

Similarly, the findings of the study regarding demographic variables showed that there were significant differences among graduate students' perceptions for the favor of male students in the first three dimensions; this could be explained that male students have more time to search where most female students are married and mothers, and on the other hand, female graduate students seems to be more realistic on their responses towards the questionnaire dimensions than male students and this could be explained that females are more serious than males towards the significance of conducting research.

Another strand of results regarding demographic variables distinguished between students in Psychological Guidance \& Counseling program and educational administration program in the total mean for the favor of Psychological Guidance \& Counseling.This result might shift the focus toward the curriculum of Psychological Guidance \& Counseling which ensure the importance of ethics commitment in their jobs;moreover, most of the research conducting by students in Psychological Guidance \& Counselingis experimental which consider more research ethics during the different stages of the research.

For the age variable, the findings revealed that graduate students less than 35 years old are more aware in general to the research ethics than the old graduate students, and this could be justified that the more students are younger the more they are more discipline towards regulations, and they have more motivation towards the originality of writing research. The findings of this study seem to be accurate from the point view of the three researchers who supervisegraduate students. Comparing this result with other some what international and Arabic relevant studies shows consistence with the reviewed literature which indicts that graduate students' perceptions and attitudes towards research ethics didn't meet the expected hopes.

\section{CONCLUSION AND IMPLICATIONS}

Several conclusions and implications could be drawn from the results of this study. First, graduate students' perception to research ethics in University of Nizwa is not too strong to conduct the research stages seriously. However, this moderate level should be managed not neglected. Second, dimension analyzing and interpreting results reveals the lowest degree of commitment compare with the other dimensions, it would be beneficial to increase students' awareness toward this stage and increase training of students and change curriculum. Further, the University of Nizwa should ensure and revisit the ethical code and curriculum to exposure students to such issues to consist with the global trend of research ethics.

Other possible conclusions and implications are the insignificant effect of most demographic variables on students' commitment; this should encourage further research to be conducted to investigate the effect of other demographic variables. Finally, it is hoped that this study will be seen as a starting point for administrators and graduate studies deanship in university of Nizwa in issues concerning research ethics for further research in change to provide valuable insight for both academics and students.

\section{References}

Aaron, R. (1992). Student academic dishonesty. Are collegiate institutions addressing the issue? NASPA Journal, 29(2), 107-113. 
Ala'wad,D. (2013). The educational role of faculty members in promoting scientific integrity among graduate students, from their point of view "field study". Unpublished

Thesis, Imam Mohamed Bin Saud Islamic University, Saudi Arabia.

Albaroudi, R. (2013). The principle of human science research ethics. Paper presented at the Annual Conference-Humanities and Educational Studies, Khartoum, Sudan.

Alebaikan, R. \&Alsemiri, L. (2016). Attitudes of graduate students at King Saud University towards digital academic integrity. Journal of Educational and Psychological Sciences, 17(1), 41-64.

ALhabeeb, A., \& Alshumari, T. (2014). Post graduate research quality at Saudi Universities in the light of adhering to research ethics. Arab Journal for Quality Assurance in Higher Education, 7(17),66-91.

Almakbeel, A. (2011). Scientific research skills of graduate students. Paper presented at the first Arab conference "future vision for promoting scientific research in the Arab

World", the Arab administrative development association, Irbid, Jordan.

Alqarni, A. (1418 H). ways of violating scientific integrity. Message of the Arabian Gulf. Riyadh. Arab Bureau of Education, 24, 91-116.

Alshayeb, A. (2005). The extent of variation of the educational research skills of the master's students in the faculties of educational sciences in Jordanian universities due to the variation in the master's program track. Jordanian Journal for educational Sciences, 1(4), 279-283.

American psychological association (2010). Ethical principles of psychologists and code of Conduct. USA: American psychological Association.

An introduction to ethics issues and principles in research involving human and animal participation. (2014). Research \& Enterprise Development Centre, Canterbury Christ University: UK.

Anfara, V. \& Mertz, N. (2006). Theoretical frameworks in qualitative research. London: Sage.

Boehm, P.; Justice, M, \& Weeks, S. (2009). Promoting academic integrity in higher Education.The Community College Enterprise, 15 (1), 45-61.

Burns, R. (1994). Introduction to research methods in education. Cheshire, England: Longman

Cohen, E.,Manion, L., \& Morrison, K. (2007). Research methods in education. ( $\left.6^{\text {th }} \mathrm{ed}\right)$. London: Routledge.

Couch, S \& Dodd, S. (2005). Doing the right thing: Ethical issues in higher education. Journal of Family and Consumer Sciences, 97(3), 20-26.

Couvalis, G. (2004).Is Induction Epistemologically Prior to Deduction?Ratio, 17, (1), pp. 28-44.

David, B., \& Resnik, J.(2015). What is Ethics in Research \& Why is it Important? National institute of environmental health science. Retrieved (April 25 2017) from: https://www.niehs.nih.gov/research/ resources/bioethics/whatis/index.cfm

Davis, G. (2003). Ethics-an educational imperative. Community College Journal, 74(3), 6-9.

De Russy, C. (2003). Professional ethics begin on the college campus. Chronicle of Higher Education, 50(4),
B20. Dictionary of Sociology.(1998), originally published by Oxford University Press 1998.

Elsayed, D., \& Kass, N. (2007). Knowledge of Sudanese researchers about research ethics.

The Research, 21, 9-11.

Ekahitanond, V. (2014).Students' perception and behavior of academic integrity: case studyof a writing forum activity. Turkish Online Journal of Distance Eduvation, 15(4), 150-161.

Hastings, A; Stockley, D; Kinderman, L \& Egan, R. (2017). Graduate student research in the classroomunderstanding the role of research ethics. College Student Journal, 50 (3), pp. 361-368.

Henrik, S \& Klauer, K. (2011). Deductive and inductive conditional inferences: Two modes of reasoning. Thinking \& Reasoning, 17, ( 3), pp. 247-281.

Ismael, A. (2010). Plagiarism in educational research. Paper presented in the $10^{\text {th }}$ conferenceof educational College. Alfaium University: Egypt.

Johnson, B. (2014). Ethical issues in shadowing research, qualitative Research in Organizations and Management: An International Journal, 9 (1) pp. 21 40.

Kandeel, N. (2014). Research ethics. Paper presented at the day of scientific research ethics, The Islamic University, Gaza, Palestine.

Kerlinger, F. (1986).Foundations of behavioral research (3rd ed.). Fort Worth, TX: Holt, Rinehart and Winston.

Kruk, J. (2013). Good scientific practice and ethical principles in scientific and higher education. Central European of Sciences and Medicine, 1(1), 25-29.

Lavallee, L \&Lesilie, L. (2017). The ethics of university and indigenous research partnerships. Innovations in Higher Education Teaching and Learning, 8, pp. 157172.

Lofstrom, E. (2012).Students' ethical awareness and conception of research ethics. Ethics \& Behavior, 22(5), 349-361.

Macfarlane, B \& Saitoh, Y.(2008). Research ethics in Japanese higher education:

Faculty attitudes and cultural mediation. Journal Academic Ethics, 6(3), pp.181-195.

Marshall, C. and Rossman, G. (1990) Designing Qualitative Research, London: Sage

Marshall, S., \& Garry, M. (2005). How well do students really understand plagiarism?

Balance, fidelity, mobility: maintaining the momentum? Australasian Society for Computers in Learning in Tertairy Eeducation, 457-467.

McNamara, C (2017). The Field Guide to Nonprofit Program Design, Marketing and Evaluation. Retrieved from:http://managementhelp.org/businessresearch/anal ysis.htm

Miller, L. (1983). Teaching research methodology and writing in the Emerald city. Paper presented at the annual meeting of the central states speech association, Lincoln, NE.

Obaidat, D., Adass, A., \& AbdAlhak, K. (1992). Scientific research: definition and Methodology. Dar Alfiker for publication, Amman: Jordan.

Pring, R. (2000). Philosophy of education research. London: Continuum DFES. 
Pupovac, V., Bilic-Zulle, L., \& Petrovecki, M. (2008). On academic plagiarism in Europe. An analytical approach based on four studies. Retrieved from:https://www.researchgate.net/publication/265753 85

Skaik, S. (2014). Research ethics and copyright. Paper presented at the day of scientific research ethics, The Islamic University, Gaza, Palestine.

Smith, D. (2003). Five principles of research ethics. American Psychological Association, 34(1), 56-60.

Spaulding, M. (2009). Perceptions of academic honest in online vs. face - to - face classrooms. Journal of Interactive Online Learning, 8(3), 183-198.

Stern, J., \& Elliott, D. (1997). The ethics of scientific research. Institute for the study of applied and professional ethics at Dartmouth College. England, NH.

Stutchbury, K., \& Fox, A. (2009). Ethics in educational research: introducing a methodology Tool for effective ethical analysis. Cambridge Journal of Education 39(4), 489-504.
Tangen, R. (2013). Balancing ethics and quality in educational research-the ethical matrix method. Scandinavian Journal of Educational Research, 58(6), 678-694.

UoN-R\& R -AMP. (2010). Copyright, cheating \& plagiarism policy 2009.Nizwa: University of Nizwa.

University of Nizwa.(2013). Research policy and regulations. Nizwa: University of Nizwa.

University of Nizwa.(2015). Intellectual property and copyright policy. Nizwa: University of Nizwa

Villatoro, J; Chang, J, \& Lane, S. (2014). Research of ethics, values and cross-cultural differences on China, Mexico or the United States. Journal of Technology Management in China, 9 (2), 133-154.

WCR12013. (2013). The $3^{\text {rd }}$ world conference on research integrity. 5-8 May. Montreal, Canada

Yusof, D. (2009). A different perspective on plagiarism. The Internet TESL Journal, XV(2), February 2009. Retrieved from: http://iteslj.org/

\section{How to cite this article:}

Rana Al-Smadi et al (2017) ' Graduate Students' Perceptions Of Scientific Research Ethics In University Of Nizwa', International Journal of Current Advanced Research, 06(04), pp. 3515-3523.

DOI: http://dx.doi.org/10.24327/ijcar.2017.3523.0306 